2011s-33

\title{
Work Absenteeism Due to a Chronic Disease
}

\author{
Guy Lacroix, Marie-Ève Brouard
}

Série Scientifique
Scientific Series

\section{Montréal \\ Mars 2011}

(C) 2011 Guy Lacroix, Marie-Ève Brouard. Tous droits réservés. All rights reserved. Reproduction partielle permise avec citation du document source, incluant la notice (C).

Short sections may be quoted without explicit permission, if full credit, including (C) notice, is given to the source.
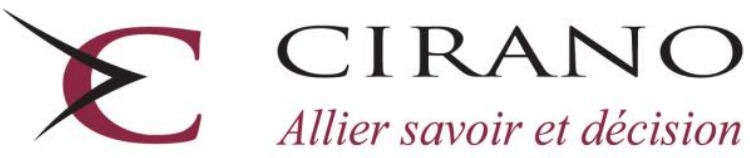

Allier savoir et décision

Centre interuniversitaire de recherche en analyse des organisations 


\section{CIRANO}

Le CIRANO est un organisme sans but lucratif constitué en vertu de la Loi des compagnies du Québec. Le financement de son infrastructure et de ses activités de recherche provient des cotisations de ses organisations-membres, d'une subvention d'infrastructure du Ministère du Développement économique et régional et de la Recherche, de même que des subventions et mandats obtenus par ses équipes de recherche.

CIRANO is a private non-profit organization incorporated under the Québec Companies Act. Its infrastructure and research activities are funded through fees paid by member organizations, an infrastructure grant from the Ministère du Développement économique et régional et de la Recherche, and grants and research mandates obtained by its research teams.

\section{Les partenaires du CIRANO}

Partenaire majeur

Ministère du Développement économique, de l'Innovation et de l'Exportation

\section{Partenaires corporatifs}

Banque de développement du Canada

Banque du Canada

Banque Laurentienne du Canada

Banque Nationale du Canada

Banque Royale du Canada

Banque Scotia

Bell Canada

BMO Groupe financier

Caisse de dépôt et placement du Québec

Fédération des caisses Desjardins du Québec

Financière Sun Life, Québec

Gaz Métro

Hydro-Québec

Industrie Canada

Investissements PSP

Ministère des Finances du Québec

Power Corporation du Canada

Raymond Chabot Grant Thornton

Rio Tinto

State Street Global Advisors

Transat A.T.

Ville de Montréal

\section{Partenaires universitaires}

École Polytechnique de Montréal

HEC Montréal

McGill University

Université Concordia

Université de Montréal

Université de Sherbrooke

Université du Québec

Université du Québec à Montréal

Université Laval

Le CIRANO collabore avec de nombreux centres et chaires de recherche universitaires dont on peut consulter la liste sur son site web.

Les cahiers de la série scientifique (CS) visent à rendre accessibles des résultats de recherche effectuée au CIRANO afin de susciter échanges et commentaires. Ces cahiers sont écrits dans le style des publications scientifiques. Les idées et les opinions émises sont sous l'unique responsabilité des auteurs et ne représentent pas nécessairement les positions du CIRANO ou de ses partenaires.

This paper presents research carried out at CIRANO and aims at encouraging discussion and comment. The observations and viewpoints expressed are the sole responsibility of the authors. They do not necessarily represent positions of CIRANO or its partners. 


\title{
Work Absenteeism Due to a Chronic Disease *
}

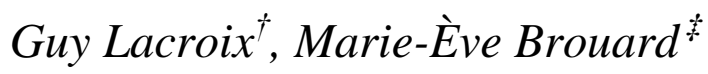

\begin{abstract}
Research on health-related work absenteeism focuses primarily on moral hazard issues but seldom discriminates between the types of illnesses that prompt workers to stay home or seek care. This paper focuses on chronic migraine, a common and acute illness that can prove to be relatively debilitating.

Our analysis is based upon the absenteeism of workers employed in a large Fortune-100 manufacturing firm in the United States. We model their daily transitions between work and absence spells between January 1996 up until December 1998. Only absences due to migraine and depression, its main comorbidity, are taken into account. Our results show that there is considerable correlation between the different states we consider. In addition, workers who are covered by the Blue Preferred Provided Organization tend to have shorter employment spells but also shorter migraine spells.
\end{abstract}

Mots clés : Migraine, absenteeism, insurance policies, transition models, unobserved heterogeneity

Keywords : I10, J32

\footnotetext{
* This paper was partly written while Lacroix was visiting ERMÈS, Université Paris-II Panthéon-Sorbonne, whose financial support and hospitality is gratefully acknowledged.

${ }^{\dagger}$ Department of Economics, Laval University, IZA, CIRPÉE, CIRANO, Guy.Lacroix@ecn.ulaval.ca

URL: http://www.ecn.ulaval.ca/Guy.Lacroix .

¥Department of Economics, Laval University, CIRPÉE.
} 


\section{Introduction}

The research of the past two decades on work absenteeism has focused primarily on moral hazard issues [Barmby (2002), Gilleskie and Lutz (2002), Gilleskie (1998), Puhani and Sonderhof (2010), Johansson and Palme (2005)]. It is usually acknowledged that insurance schemes tend to lengthen the spells of absenteeism [Gilleskie (1998, 2010), Barmby (2002), Puhani and Sonderhof (2010)], although their impact on the incidence of absenteeism per se is not so clear-cut. While the empirical research has found that men are more sensitive to financial incentives [Vistnes (1997), Gilleskie (2010)], the relative importance of socio-economic characteristics and financial incentives in explaining the length of work absences has not yet been settled [Vistnes (1997), Barmby et al. (2004)]. ${ }^{1}$

The empirical literature on health-related work absenteeism focuses for the most part on acute or temporary illnesses [Gilleskie $(1998,2010)$, Cockburn et al. (1999)]. While concern for moral hazard is still very much at the heart of the research, some have found that insurance schemes or sick pay policies may be beneficial to both firms and individuals. Indeed, employerprovided health insurance can improve productivity by enhancing workers' health status and work effort, thereby reducing absenteeism and workmen's compensation [Nguyen and Zawacki (2009)]. Beneficial impacts on worker turnover have also been found, although this is still disputed [Gilleskie and Lutz (2002)]. Another strand of the literature has generally found work absenteeism to be relatively sensitive to publicly mandated sick leave policies, although the majority of papers do not account explicitly for the type of illness motivating the absence [see Henrekson and Persson (2004) for an analysis of the Swedish case, and Ziebarth and Karlsson (2010) and Puhani and Sonderhof (2010) for the German case].

Most empirical studies do not discriminate between the types of illnesses that prompt workers to stay home or seek care. Yet the incidence and duration of absence spells, and their responsiveness to financial incentives, certainly depend upon the nature of the health shock. In this paper we focus on chronic migraine, a common and acute illness that can prove to be rel-

\footnotetext{
${ }^{1}$ Ichino and Moretti (2009) have recently found that menstruation can explain a significant share of female absenteeism and earnings gap. Likewise, Brown et al. (1999) have found that profit-sharing schemes and share ownership in French enterprises significantly reduce work absenteesim.
} 
atively debilitating. ${ }^{2,3}$ Indeed, migraines can last anywhere between 4 and 72 hours [Evans and Mathew (2000)], are often associated with other symptoms such as nausea and photophobia which can be more debilitating than the headache per se [Evans and Mathew (2000)], and cause approximately $30 \%$ of migraineurs to be bedridden [Pryse-Phillips et al. (1992)]. More importantly, chronic migraine is often associated with various psychiatric disorders such as anxiety, agoraphobia and depression. ${ }^{4}$

Workers who suffer from chronic migraine need not always stay away from work each time an episode strikes. ${ }^{5}$ Because work absenteeism in the manufacturing sector can be costly if production is disrupted or significantly disturbed, it is important to determine whether migraine-related absenteeism responds to financial incentives. Our analysis thus focuses on the absenteeism of workers employed in a large Fortune-100 manufacturing firm in the United States who are diagnosed with chronic migraine. We model their daily transitions between work and absence from January 1996 up until December 1998. Only absences due to migraine and depression, its main comorbidity, are taken into account. Workers could subscribe to three different insurance packages with varying premiums. Our goal is to determine whether there is any indirect evidence that both the frequency and the duration of absence spells are affected by the type of insurance policy that are available to the workers.

The paper is structured as follows. Section 2 presents the sample and prima facie evidence on the link between medication, insurance and the duration of absence spells. Section 3 presents the econometric model. We also show how potential selectivity issues arising from the choice of a particu-

\footnotetext{
${ }^{2}$ Migraine is a common disease in the United States. Its prevalence is estimated at $13.2 \%$ among those aged between 18 and 65 [Evans and Mathew (2000), Schwartz et al. (1997)] and is highest among the working age population [Lipton et al. (2007)]. The economic burden, including absenteeism, lower productivity and medical costs, is estimated at about 50 billion U.S. [National Headache Foundation (2010)]

${ }^{3}$ The only other study we know of that looks at the relationship between migraines and insurance status is that of Wilper et al. (2010). They report that individuals with no insurance or Medicaid were less likely than the privately insured to receive abortive therapy or prophylactic therapy.

${ }^{4}$ Breslau and Davis (1993) estimate that chronic migraineurs are 4.2 times more likely to suffer from depression than otherwise healthy individuals. See also Senaratne et al. (2010).

${ }^{5}$ It is estimated that only half of episodes require a leave from work [Caro et al. (2001)] but of those, the majority require treatment [Clouse and Osterhaus (1994)]. Yet the productivity of those who remain at work may nevertheless be seriously negatively impacted [see, e.g. Cockburn et al. (1999)].
} 
lar insurance package are dealt with. The transition model along with the unobserved heterogeneity specification are presented in details. Section 4 presents the main results. Finally Section 5 concludes the paper.

\section{Data and Setting}

\subsection{Migraines and Available Treatments}

Migraines are characterized by unilateral or bilateral headaches in $60 \%$ and $40 \%$ of cases, respectively. The intensity of the pain is related to the extent of the vasodilatation and the hyperpulsatility of the arteries of the brain. Migraines usually consist of four phases: prodrome, aura, headache and postdrome [Evans and Mathew (2000)]. The prodrome, which occurs 24 hours before the onset of the aura is a period of tiredness, irritability and loss of concentration. The aura, in turn, consist of visual disturbances including blind spots and/or flashes. The aura occurs about an hour before the onset of the migraine. The third phase is accompanied by headache symptoms (nausea, photophobia). Finally, the postdrome is characterized by fatigue and exhaustion. It can last a few hours or several days [Evans and Mathew (2000)]. Over half of all individuals suffering from migraine have to leave work when an episode strikes and most seek medical treatment.

Three main drug groups can be used to treat migraines: analgesics (painkillers), ergot alkaloids and triptans. Analgesics simply act on the pain and are often used to treat mild headaches [Antonaci et al. (2010)]. The ergot alkaloids are vasoconstrictors that are used to treat moderate to severe migraines [US Headache Consortium (2000)]. Finally, triptans (sumatriptan, rizatriptan, naratriptan and zolmitriptan) are serotonin receptor agonists. They are also used to treat spells of moderate to severe migraines [US Headache Consortium (2000)] but are much more expensive than alkaloids.

\subsection{Data and Sampling Scheme}

The main goal of this paper in to determine whether variation in duration and occurrence, conditional on severity, is partly linked to financial incentives. In order to achieve this, we need very precise and detailed data. Our analysis is based on the claims records of a national Fortune-100 American corporation with more than 100,000 employees. The files contains health care and disability information for the period spanning 1996 through 1998. For each person in the file, the records show the year of birth, sex, state of residence, type of health plan and treatment. Expenditures for each worker's claims paid by the employer during the period of enrolment were recorded by 
date of service and nature of the ailment. Periods of disability and payments received from the corporation were recorded, as were dates of medical care.

Diagnoses are coded using the International Classification of Diseases, Ninth Edition (ICD-9), and drugs are categorized according to the National Drug Code (NDC). To be included in our sample, workers had to have filed at least one migraine-related claim between January $1^{\text {st }} 1996$ and December $31^{\text {st }} 1998 .{ }^{6}$ Individuals suffering from cancer (ICD-9: 140-239), infections (ICD-9: 036.0-036.9, 320.0-320.9), cluster headaches (ICD-9: 346.2), hemiplegic or ophtalmoplegic migraines (ICD-9: 346.8) are excluded from the sample. These exclusion criteria are standard in the medical literature [Schulman et al. (2001)]. In addition, workers 65 years of age and over are excluded to avoid retirement-related issues. Finally, individuals in our sample had to be covered by one of three insurance policies offered by the employer for the whole period. The three insurance plans are the Blue Standard Plan (BSP), the Blue Preferred Provider Organization (BPPO), and the SelectCare PPO (SCPPO). All three plans offer members discounts when they obtain care from within the plans' network. Members can self-refer to any physician or provider in the network. Care can be sought outside the network but out-of-pocket expenses are usually higher.

Workers in our sample were treated with two different drugs when treatment was deemed required. The first will be referred to as a "Drug A". It is a combination medication containing isometheptene (vascular constrictor), acetaminophen (analgesic), and dichloralphenazone (mild sedative). The second will be referred to as "Drug B" and is triptan sulfa drug containing a sulfonamide group. While both drugs can be used to treat severe migraines, drug $\mathrm{A}$ is more often used to treat mild migraines and drug B is more often used to treat severe migraines. The use of a particular drug will proxy for the severity of a given migraine spell.

\subsection{Descriptive Statistics}

The data files at our disposal contain information on 60,622 employees. Of this total, only 1,236 workers reported ever suffering from migraines and fewer than 543 sought treatment at least once between 1996 and 1998. Our analysis focuses on this subgroup of employees. Applying the exclusion restrictions further reduced our sample size to 303 observations. ${ }^{7}$

\footnotetext{
${ }^{6}$ Migraines are coded ICD-9 $=346.0,346.1,346.9$.

${ }^{7}$ We discarded 240 additional observations for the following reasons: 76 individuals were not employed continuously during our study window, 149 were diagnosed with cancer, and 15 were diagnosed with cluster or hemiplegic migraines.
} 
Table 1 presents the main characteristics of our sample. Males and Females employees are equally represented in our data. Most reside in the north-eastern region of the country. A significant proportion live in rural areas as many plants are located outside city centres. The majority of employees are covered by the Blue Preferred PPO insurance policy, whereas the Blue Standard and SelectCare PPOs cover more or less $10 \%$ each of the workforce. Unfortunately, we have no information on the specificities of individual contracts. The empirical analysis will therefore be limited to assessing the mean impact of the different insurance policies on individual behaviour, if any. The last section of the table shows that workers are more likely to use Drug B when a migraine occurs. As mentioned earlier, Drug A are less expensive than Drug B and is usually recommended for the treatment of less acute migraines. ${ }^{8}$

Table 1: Summary Statistics

\begin{tabular}{lcc}
\hline Variable & Percentage & Std-Dev \\
\hline Demographics & 49.308 & \\
Male & 41.749 & \\
Rural area & 78.359 & \\
North-East & 39.618 & 8.738 \\
Age & & \\
Insurance Plan & 79.545 & \\
Blue Preferred PPO & 9.782 & \\
Blus Standard PPO & 10.473 \\
SelectCare PPO & & \\
Treatment & 33.862 \\
Drug A & 67.461 \\
Drug B & \multicolumn{2}{c}{303} \\
\hline Number of observations
\end{tabular}

Table 2 reports the mean duration and mean frequency of various states, broken down by insurance policy. ${ }^{9}$ The table shows that irrespective of the state we consider, employees covered by the BSP have longer work and absence spells. Absences due to treated and untreated migraines last almost

\footnotetext{
${ }^{8}$ In a recent study, Freitag et al. (2001) found no statistically significant differences in headache recurrence over a 24 -hour evaluation period for those patients responding in the first 4 hours. In those with headache recurrence, it was statistically significantly more severe in those patients treated with sumatriptan succinate. The study concluded that both treatments are effective when used early in the treatment of an acute migraine.

${ }^{9}$ The figures are tabulated as of the first spell of migraine to occur between 1996 and 1998 for each worker.
} 
twice as long as those of employees covered by the BPPO and SelectCare policies. For obvious reasons, longer spells tend to occur less frequently over the data window.

Table 2: Mean Duration and Frequency of Spells, by Insurance Plan ${ }^{\dagger}$

\begin{tabular}{|c|c|c|c|c|c|c|}
\hline \multirow[b]{2}{*}{ Insurance plan } & \multicolumn{3}{|c|}{ Mean duration } & \multicolumn{3}{|c|}{ Mean frequency } \\
\hline & $\mathrm{BSP}$ & BPPO & Select & $\mathrm{BSP}$ & $\mathrm{BPPO}$ & Select \\
\hline \multirow[t]{2}{*}{ Untreated migraines } & 4.096 & 1.385 & 1.109 & 1.741 & 2.738 & 2.000 \\
\hline & $(11.790)$ & $(9.666)$ & $(0.899)$ & $(1.607)$ & $(2.687)$ & $(1.859)$ \\
\hline \multirow[t]{2}{*}{ Treated migraines } & 7.681 & 1.759 & 3.511 & 1.500 & 1.905 & 1.692 \\
\hline & $(7.689)$ & $(5.581)$ & $(6.728)$ & $(0.859)$ & $(2.208)$ & $(1.543)$ \\
\hline \multirow[t]{2}{*}{ Depression } & 20.583 & 7.874 & 20.079 & 3.000 & 3.536 & 9.000 \\
\hline & $(16.995)$ & $((14.896)$ & $(16.998)$ & $(2.366)$ & $(4.647)$ & $(11.314)$ \\
\hline \multirow[t]{2}{*}{ Work } & 231.096 & 183.935 & 196.219 & 2.302 & 3.655 & 2.892 \\
\hline & $(242.256)$ & $(190.144)$ & $(242.563)$ & $(2.315)$ & $(4.143)$ & $(3.430)$ \\
\hline
\end{tabular}

†Notes:

1. Duration is expressed in day. The frequencies are computed over 1996-1998.

2. Standard deviation between parentheses.

3. Work duration does not account for right censoring.

Table 3 focuses on the relation between spell duration, frequency and medication. The mean in each column is computed using individuals who have only used Drug A or Drug B, respectively, for each spell of migraine they experienced. Individuals who alternated between the two are not included in the calculations. With the exception of untreated migraines, individuals who use Drug B have shorter migraine spells, depression spells and work spells. Their untreated migraine spells are longer but have a much larger standard deviation. On the other hand, workers who are treated with Drug B seem to experience more frequent spells of migraines (treated or not) and depression.

Finally, a number of papers [see, e.g. Barmby et al. (1991), Barmby (2002)] have found that absence spells often begin on fridays or mondays. This can simply result from the censoring of sickness spells which might have started on Saturday or Sunday. Yet, because migraine spells are relatively short, a high concentration of spells beginning on either weekdays may indicate that workers respond positively to financial incentives to seek care and stay home. Figure 1 reveals no such pattern for either type of migraines. The distribution is relatively flat, except for saturdays and sundays, reflecting the fact that few workers work on weekends. 
Table 3: Mean Duration and Frequency of Spells, by Treatment ${ }^{\dagger}$

\begin{tabular}{lccccc}
\hline \multirow{2}{*}{$\begin{array}{c}\text { Medication } \\
\text { Untreated migraines }\end{array}$} & Drug A & Drug B & \multicolumn{2}{c}{ Drug A } & Drug B \\
\cline { 2 - 5 } & 0.810 & 1.412 & 1.242 & 1.612 \\
Treated migraines & $(0.959)$ & $(6.084)$ & $1.779)$ & $(2.765)$ \\
& 3.283 & 1.965 & 1.626 & 2.163 \\
Depression & $(9.571)$ & $(3.751)$ & $(1.397)$ & $(2.361)$ \\
& 12.214 & 6.440 & 0.667 & 0.736 \\
Work & $(26.668)$ & $(8.854)$ & $(2.603)$ & $(2.893)$ \\
& 230.624 & 172.541 & 3.586 & 4.543 \\
& $(207.684)$ & $(193.464)$ & $(3.606)$ & $(5.078)$ \\
\hline \hline
\end{tabular}

${ }^{\dagger}$ Notes:

1. Duration is expressed in day, and the frequencies are computed over 1996-1998.

2. Standard deviation between parentheses.

3. Employment duration does not account for right censoring.

Figure 1: Beginning Day of Migraine Spells

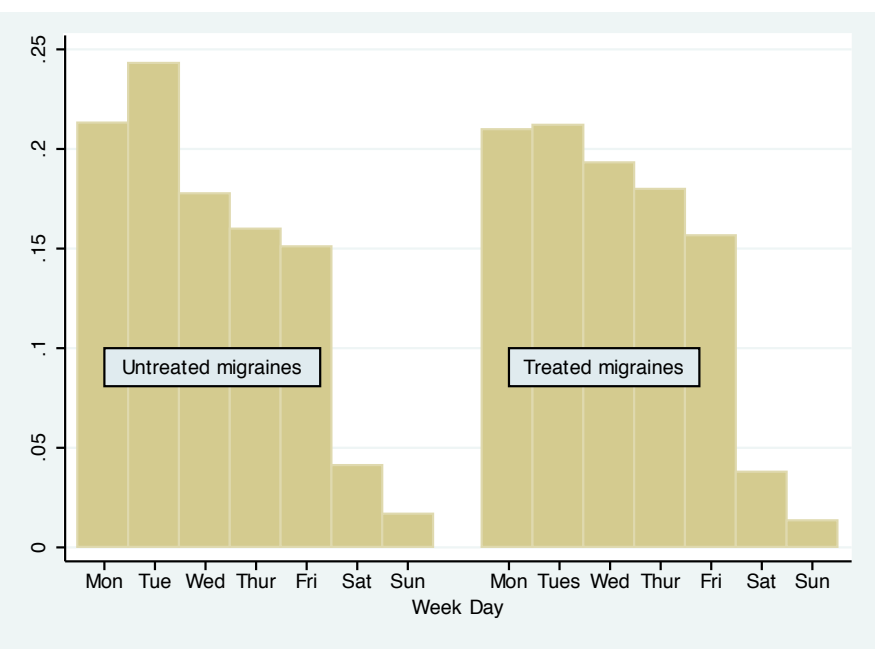

\subsection{Prima Facie Evidence}

The previous tables suggest that the duration and frequency of absenteeism might be loosely related to the type of insurance coverage. To the extent the type of treatment proxies the severity of the migraine spells, the relation between absenteeism and insurance needs to conditioned on the 
severity of the migraine spells. ${ }^{10}$ We investigate this crudely by looking at the individual quarterly count of absence spells. This allows us to control for quarterly fixed effects in addition to demographic variables. Focusing on quarterly data rather than the 3-year sample window necessarily increases the number of zero counts. We thus use a Poisson hurdle model. The hurdle model relaxes the assumption that the zeros and the positives come from the same data-generating process. A zero count may indeed result from the fact that no migraine spell was experienced by the worker or conversely that he decided not to seek care even if one did occur. On the other hand, conditional on having experienced a migraine spell, the number of quarterly absence spells may depend upon an entirely different process. The zeros are determined by the density $f_{1}(\cdot)$, so that $P(y=0)=f_{1}(0)$. The positive counts come from the truncated density $f_{2}(y \mid y>0)=f_{2}(y) /\left(1-f_{2}(0)\right)$. The density of the count is thus given by:

$$
g(y)=\left\{\begin{array}{r}
f_{1}(0) \text { if } y=0 \\
{\left[\frac{1-f_{1}(0)}{1-f_{2}(0)}\right] \times f_{2}(y) \text { if } y>0 .}
\end{array}\right.
$$

For our purposes, we assume that $f_{1}(\cdot)$ is logit and $f_{2}(\cdot)$ is Poisson. Maximum likelihood estimation of the logit-Poisson model is straightforward as each density can be estimated separately.

The results of fitting the model are reported in Table 4 . The specifications includes all the covariates that are available in the administrative files. The files include few individual characteristics, but the specification if very similar to that found in Wilper et al. (2010). The table distinguishes between the total number of individual quarterly absences and those absences that are motivated by the onset of a migraine or a depression. The left-hand side column of each specification focuses on the logit specification, i.e. $f_{1}(\cdot)$, while the right-hand side column focuses on the poisson process, i.e. $f_{2}(\cdot)$. The parameter estimates show no particular pattern. Hence, age, gender, rural and northern regions all have an effect on either the logit or the Poisson process of one or more specifications. The more interesting results concern the parameters of the insurance dummy variables. Indeed, it turns out that being insured with either the Blue Standard or the Blue Preferred insurance policies has a significant negative impact both on the likelihood of missing work at all during a given quarter (save for depressions) and the number of absence spells, conditional on being greater than zero (censored Poisson)

\footnotetext{
${ }^{10}$ The data reveal no statistically significant relation between insurance policies and medication. A simple contingency test yields $\chi^{2}(1)=0.343$ with a $\mathrm{P}$-value of 0.558 .
} 
relative to workers covered by the SelectCare PPO. In addition, the quarterly dummy variables show that there is considerable variations in the probability of experimenting an absence spell. The number of spells per se does not depict such a sensitivity, except when pooling all spells together. ${ }^{11}$

\section{Transition Model}

The previous section brought to bear evidence that the frequency and the occurrence of absence spells may be linked to the type of coverage provided by the insurance policy. Our data is rich enough to allow modelling the transitions between work and absence jointly. To do so we use a multi-state multi-episode transition model. To illustrate the approach, Figure 2 depicts the history of hypothetical worker over the sample window. The dashed vertical lines delimit the period of observation. Thus as of January 1996, the worker in our example was in the midst of a work spell that lasted until June 1997. A spell of (untreated) migraine forced her away from work for a couple of days. After returning to work for a few weeks, she then suffered a severe spell of migraine that required treatment and eventually lead to spell of depression. Finally, her last employment spell is censored at the end of December 1998.

Figure 2: Employment History of a Hypothetical Worker

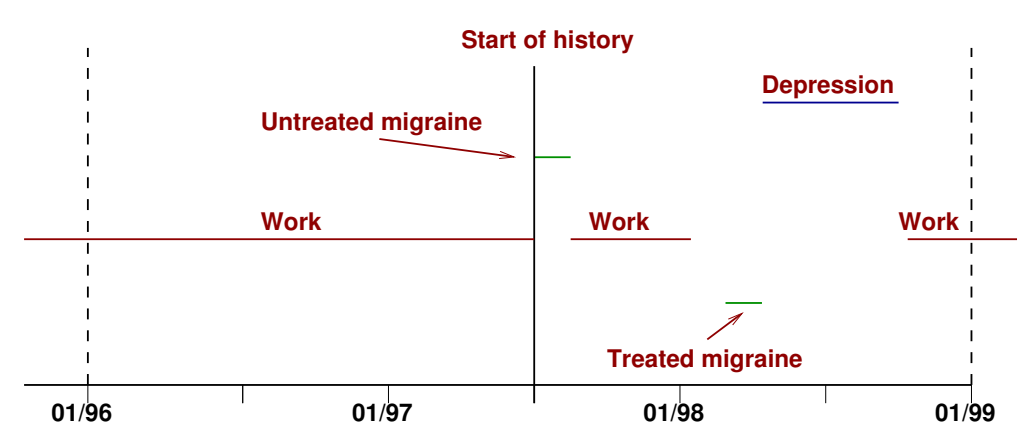

The figure illustrates the complexity of individual histories. It also underscores the many statistical challenges that must be tackled. To start

\footnotetext{
${ }^{11}$ There is too little variation in the number of depression spells quarterly-wise to introduce quarter fixed effects.
} 


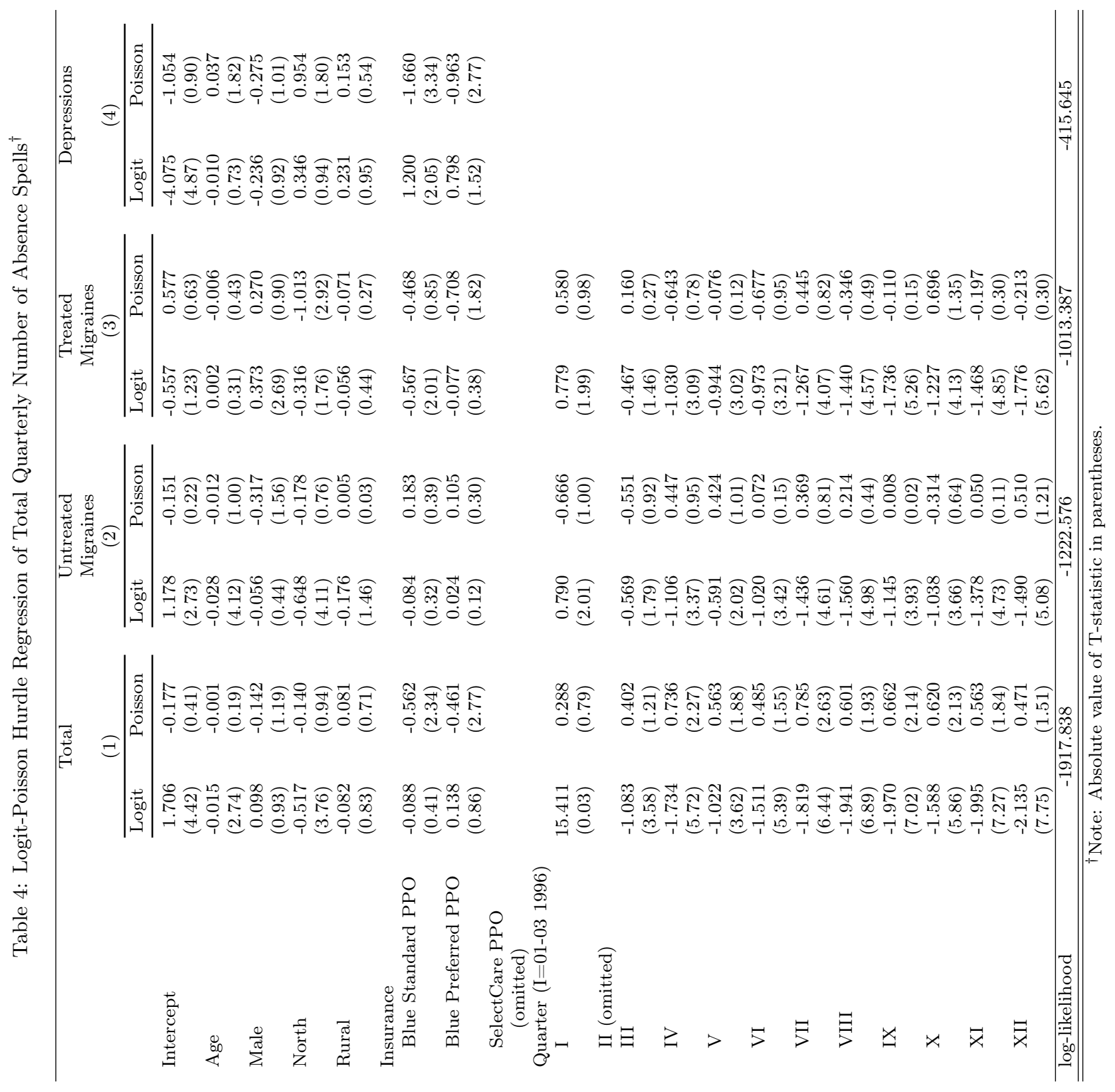


with, we must acknowledge that the initial migraine spell is not random. Indeed it is itself the result of a sequence of transitions that predates January 1996 and which are potentially linked to observed and unobserved individual characteristics. Further, the potential self-selectivity into the insurance policies must be addressed carefully. Finally, the right-censored spells must also be treated explicitly. Fortunately, the multi-state multi-episode model can relatively easily account for all these complexities.

An additional benefit of the multi-state multi-episode model is to allow past occurrences of migraine spells to impact the likelihood of current spells of migraine, depression and employment. In addition, observed and unobserved heterogeneity can easily be incorporated into the model. Such heterogeneity is a potentially important determinant of the type of coverage a worker may choose.

\subsection{Modelling individual histories}

Table 5 shows the transitions that were experienced by the individuals in our sample between 1996 and 1998. Overall, the 303 workers made over 2,024 transitions. Not surprisingly, nearly every migraine and depression spells end with a transition back to work. The table also shows that the transitions between treated and untreated migraines and depression are simply too few to be considered. Although not shown, our data also reveal that over $90 \%$ of all migraine spells last less than a day and more than $69 \%$ last only half a day. Because there if little variation in duration, we will treat migraine spells as discrete events. Work and depression spells, on the other hand, depict large duration variation. These will thus be modelled explicitly.

Table 5: Observed Transitions

\begin{tabular}{l|cccc|c}
\hline Origin/Destination & $\begin{array}{c}\text { Untreated } \\
\text { Migraine }\end{array}$ & $\begin{array}{c}\text { Treated } \\
\text { Migraine }\end{array}$ & Depression & Work & Total \\
\hline Untreated migraine & - & 0 & 1 & 489 & 490 \\
Treated migraine & 0 & - & 1 & 377 & 378 \\
Depression & 0 & 1 & - & 144 & 145 \\
Work & 490 & 377 & 143 & - & 1,012 \\
\hline \multicolumn{1}{c}{ Total } & 489 & 378 & 145 & 1,012 & 2,024 \\
\hline
\end{tabular}

Let $m$ denote the total number of episodes experienced by a given individual. The claims data are arranged so that individuals are initially observed away from work due to the onset of an untreated or a treated migraine. Naturally, the initial state is itself endogenously determined by previous transitions and observable and unobservables variables. This "initial conditions" 
problem has been extensively studied in the literature [see, e.g. Brouillette and Lacroix (2010), Gritz (1993), Heckman and Singer (1984)]. Here we follow Wooldridge (2005) and treat the initial state as exogenous but condition all the following transitions on $r_{0}$, the initial state. Let $U$ denote an untreated migraine, $T$ a treated migraine, $D$ a depression spell, and $W$ a work spell. Each work episode is characterized by its duration and the state that succeeds it (destination state). Write the endogenous variables as $\left(\delta_{j}, r_{j}\right)$, where $\delta_{j}$ is the duration of the $j^{\text {th }}$ episode and $r_{j}$ is the destination state that brings it to an end, $j=1, \ldots, m-1$ [see Lawless (2003), Mealli and Pudney (2003)]. More precisely, let $f^{W}\left(\delta_{j}, r_{j} \mid X_{j}, \nu, r_{0}\right)$ be the joint density of the duration and destination state of the $j^{\text {th }}$ employment spell. The density is conditional on a vector of observed characteristics which may include earlier state and duration variables to allow for occurrence dependence. ${ }^{12}$ The variables are all spell-specific and are assumed constant over the duration of a given spell. Similarly, let $f^{D}\left(\delta_{j} \mid X_{j}, \nu, r_{0}\right)$ be the density of the duration of the $j^{\text {th }}$ depression spell. ${ }^{13}$ The term $\nu$ is a vector of unobserved individual random effects that are constant over time. This constancy is likely to generate serial dependence in the sequence of episodes. The last observed spell is necessarily still in progress in December 1998 [see Figure 2]. Its distribution is thus characterized by a survivor function, $S^{W}\left(\delta_{m} \mid X_{m}, \nu\right)$.

As mentioned above, we treat migraine spells as discrete events. We thus model the probability that a given spell lasts half a day (as opposed to more than half a day). The probability that this occurs is given by $\operatorname{Pr}^{K}\left(\delta_{j} \leq\right.$ $\left.1 / 2 \mid X_{j}, \nu, r_{0}\right)$, where $K=U, T$. Finally, selection into a particular insurance policy must be accounted for. The majority of the workers in our sample are covered by the Blue Preferred Provider Organization (220/303). The two other policies are equally important (43 for BSP and 40 for SelectCare). Because there are too few workers subscribing to the latter two policies, with lump them into a single category and model the choice between BPPO and this other aggregate policy. We thus write $P^{\mathrm{INS}}(\mathrm{BPPO}=1 \mid X, \nu)$. The probability is not conditioned on the initial state because the choice of a particular policy was made at the time of hiring and predates the first spell of migraine.

\footnotetext{
${ }^{12}$ See Doiron and Gorgens (2008) for a recent and in-depth analysis of state dependence in labour market outcomes.

${ }^{13}$ Because all the depression spells end in a transition to employment, there is no need to model the destination state.
} 
The likelihood function of a sequence of transitions is given by:

$$
\begin{aligned}
& f(\cdot)=P^{\mathrm{INS}}(\mathrm{BPPO}=1 \mid X, \nu) \times \\
& {\left[\prod_{j=1}^{m-1} f^{W}\left(\delta_{j}, r_{j} \mid \cdot\right)^{W=1} f^{D}\left(\delta_{j} \mid \cdot\right)^{D=1} P^{T}\left(\delta_{j} \leq 1 / 2 \mid \cdot\right)^{T=1} P^{U}\left(\delta_{j} \leq 1 / 2 \mid \cdot\right)^{U=1}\right] \times} \\
& S^{W}\left(\delta_{m} \mid X_{m}, \nu, r_{0}\right),
\end{aligned}
$$

where the subscripts indicate which transition occurs during the $j^{\text {th }}$ spell, and where each term inside the square brackets is conditioned upon $X_{j}, \nu, r_{0}$. Because the error terms $\nu$ are unobserved, we must specify a distribution function, $G(\nu)$, say, to make equation (1) an estimable econometric model. Obviously, the computation of the multi-dimensional integral over the domain of $\nu$ is technically demanding. As is now customary, we approximate the integral by an average over $H$ pseudo-random deviates. Let $\hat{l}_{i}\left(\nu^{h}\right)$ denote the contribution of individual $i$ to the log-likelihood function for a given draw $\nu^{h}$. The approximate log-likelihood we maximize is the following:

$$
\widehat{\ln L}=\sum_{i=1}^{N} \ln \left(\frac{1}{H} \sum_{h=1}^{H} \hat{l}_{i}\left(\nu^{h}\right)\right),
$$

where $H$ is the number of draws. The maximization of the simulated likelihood function yields consistent and efficient parameter estimates if $\sqrt{N} / H \rightarrow$ 0 when $H \rightarrow+\infty$ and $N \rightarrow+\infty$ [see (Gourriéroux and Monfort, 1991; Gouriéroux and Monfort, 1996)]. ${ }^{14}$

\subsection{Transition intensity and probability functions}

The transition components of the model, $\left[f^{W}(\cdot)\right.$ and $\left.S^{W}(\cdot)\right]$, give the instantaneous probability of exit from work to a specific destination at a particular time conditional on no previous exit having occurred. Thus, for a given episode the $l^{\text {th }}$ transition intensity function $\lambda_{l}^{W}\left(t \mid X, \nu, r_{0}\right)$ if given by:

$$
\operatorname{Pr}\left(r=l, \delta \in(t, t+d t) \mid \delta \geq t, X, \nu, r_{0}\right)=\lambda_{l}^{W}\left(t \mid X, \nu, r_{0}\right) d t
$$

\footnotetext{
${ }^{14}$ While the literature has established that $H=20$ appears adequate [see Laroque and Salanié (1993), Kamionka (1998)], we have chosen $H=100$ even though the slope parameters are relatively insensitive to the number of draws we use.
} 
where $\mathrm{X}$ is spell-specific as mentioned above. The joint probability of exit route $r$ and duration $\delta$ is given by:

$$
f^{W}\left(\delta, r \mid X, \nu, r_{0}\right)=\lambda_{r}^{W}\left(\delta \mid X, \nu, r_{0}\right) \exp \left[-\sum_{l \neq W} I_{l}^{W}\left(\delta \mid X, \nu, r_{0}\right)\right],
$$

where $I_{l}^{W}\left(\delta \mid X, \nu, r_{0}\right)$ is given by:

$$
I_{l}^{W}\left(\delta \mid X, \nu, r_{0}\right)=\int_{0}^{\delta} \lambda_{l}^{W}\left(t \mid X, \nu, r_{0}\right) \mathrm{d} t
$$

The transition intensity function we use is of the Weibull type:

$$
\lambda_{l}^{W}\left(t \mid X, \nu, r_{0}\right)=\alpha_{l} t^{\alpha_{l}-1} \exp \left(-X^{\prime} \beta_{l}-\gamma_{l} r_{0}\right) \exp (-\nu),
$$

$\alpha_{l} \in \mathbb{R}$. If $\alpha_{l}>1$ then the hazard function is increasing with respect to $t$. Conversely, if $\alpha_{l}<1$ then the hazard is decreasing with respect to $t$, while if $\alpha_{l}=1$, then the hazard function is constant. ${ }^{15}$ The associated survival function is given by:

$$
S^{W}\left(t \mid X, \nu, r_{0}\right)=\exp \left[-\exp \left(-X^{\prime} \beta_{l}-\gamma_{l} r_{0}\right) \exp (-\nu) \sum_{l \neq W} t^{\alpha_{l}}\right]
$$

where $X$ is a row-vector of observable characteristics (including possibly past occurrence of migraines), $\beta_{l}$ is an appropriately dimensioned destinationspecific vector of parameters, and $\alpha_{l}$ are also destination-specific parameters. The parameters $\gamma_{l}$ measure the impact of the initial state on each type of transition.

The density function (1) involves three probabilities. The first concerns the type of insurance coverage and the other two relate to the probabilities that treated and untreated migraine spells last half a day. All three

\footnotetext{
${ }^{15}$ The hazard function of the Weibull model with unobserved heterogeneity need not be monotonic. In fact, if the the unobserved heterogeneity follows a Gamma distribution, then the hazard function is non-monotonic and is known as the Singh-Maddala function [see Kamionka and Lacroix (2008)].
} 
probabilities are modelled using a logistic distribution:

$$
\begin{aligned}
P^{\mathrm{INS}}(\mathrm{BPPO}=1 \mid X, \nu) & =\frac{\exp \left(X \beta_{I}+\nu\right)}{1+\exp \left(X \beta_{I}+\nu\right)} \\
P^{T}\left(\delta \leq 1 / 2 \text { day } \mid X, \nu, r_{0}\right) & =\frac{\exp \left(X \beta_{T}+\gamma_{T} r_{0}+\nu\right)}{1+\exp \left(X \beta_{T}+\gamma_{T} r_{0}+\nu\right)} \\
P^{U}\left(\delta \leq 1 / 2 \text { day } \mid X, \nu, r_{0}\right) & =\frac{\exp \left(X \beta_{U}+\gamma_{U} r_{0}+\nu\right)}{1+\exp \left(X \beta_{U}+\gamma_{U} r_{0}+\nu\right)}
\end{aligned}
$$

\subsection{Unobserved heterogeneity}

The next issue that must be addressed to make the model amenable to estimation is to specify the manner in which unobserved heterogeneity enters the above specification. Most applications rely on the work of Heckman and Singer (1984) and approximate arbitrary continuous distributions using a finite number of mass points [see Gritz (1993), Ham and Rea (1987), Doiron and Gorgens (2008)]. A number of recent papers use flexible specifications that allow the heterogeneity terms to be correlated across states [see Ham and LaLonde (1996), Eberwein et al. (2002)]. These specifications are sometimes referred to as single or double-factor loading distributions and are also based on a finite set of mass points.

The approach proposed by Heckman and Singer (1984) is impractical in our setting as it would involve too many parameters. Instead we use a two-factor specification, where each of the two random effects are constant over time and linked to a particular state of origin. To fix ideas, let $\nu=\left(\nu_{1}, \ldots, \nu_{K}\right)$ be a vector of unobserved heterogeneity variables, with $\nu_{k}$ an origin-specific component $(k=1, \ldots, 4)$. Consider a two-factor loading model [see Van den Berg (1997)] such that

$$
\nu_{k}=\left\{\begin{array}{cl}
\exp \left(\theta_{k}^{1} \xi_{1}+\theta_{k}^{2} \xi_{2}\right) & \text { if } k \in\{\mathrm{W}, \mathrm{D}\} \\
\theta_{k}^{1} \xi_{1}+\theta_{k}^{2} \xi_{2} & \text { if } k \in\{\mathrm{INS}, \mathrm{T}, \mathrm{U}\}
\end{array}\right.
$$

where $\nu_{k}$ is the random effect associated with state $k, \theta_{k}^{1}$ and $\theta_{k}^{2}$ are loading factors for state $k$, and $\xi_{1}$ and $\xi_{2}$ are independent random draws from the standard normal distribution. ${ }^{16}$ To insure identification of the parameters, we impose $\theta_{k}^{1}=1, k \geq 2$ and $\theta_{1}^{2}=1$.

\footnotetext{
${ }^{16}$ A similar approach has been used by Bonnal et al. (1997), Mealli and Pudney (2003) and Brouillette and Lacroix (2010).
} 


\section{Econometric Results}

Table 6 presents the parameter estimates of the transition model. The table is divided vertically into two parts. Columns (1)-(3) present the parameter estimates of the discrete variables, i.e. type of insurance and duration (half a day vs longer) of treated and untreated migraines. Columns (4)-(7) focus on the duration of employment and depression spells. The table is also divided horizontally into five parts. The top panel looks at the impact of observable individual characteristics on outcome variables. ${ }^{17}$ The second and third panels focus on past duration and beginning and ending-day-ofweek effects, respectively. The fourth panel presents estimates of the effect of insurance and medication on the duration of different spells. As mentioned earlier, because BPPO was the most prevalent insurance policy, we contrast the impact of this insurance policy with respect to the other two. Finally, the last panel presents the estimates of the ancillary parameters of the model.

\subsection{Shape and slope parameters}

We begin our discussion of the econometric results with the Weibull shape parameters. These characterize the duration dependence. The parameter estimate in the state of depression is not statistically different from zero. This implies that the hazard rate is flat, i.e. that the probability of leaving the state of depression is independent of the duration [see equation (4)]. The hazard rates out of employment, on the other hand, are all monotonically decreasing irrespective of the state of destination. In other words, the conditional probability of leaving work due to a migraine or a depression decreases with the duration of the work spell.

Recall that all the density functions are conditioned on the initial state, $r_{0}$ (untreated migraine). The parameter estimates show that the initial state has no impact on the duration of future treated and untreated migraines or depressions. On the other hand, future employment spells need to be conditioned on the initial spell. Indeed, workers first observed suffering from an untreated migraine will have shorter work spells ending in a depression or a treated migraine, and longer work spells ending in an untreated migraine than workers first observed suffering from a treated migraine.

\footnotetext{
${ }^{17}$ We can not control for the region of residence in the duration of depression spells because the majority of individuals experiencing such spells live in the North (121 out of 135 , or $89.7 \%$ ).
} 
To the extent our specification adequately accounts for potential selectivity in the various states, the slope parameters can be considered void of systematic biases. We thus turn to the top panel of the Table 6. The parameter estimates of the demographic variables show interesting results. To begin with, it seems older employees and those from the northern region and rural areas are less likely to subscribe to the BPPO insurance policy. The probability that a spell of migraine lasts less than half a day is higher for male workers if the migraine does not require treatment. Otherwise, there appears to be no differences between male and female workers. The slope parameters of the duration model tell an interesting story. First, the duration of a depression spell is found to be independent of individual characteristics. In fact the only covariate that has any explanatory power on the duration is the use of an antidepressant drug: Workers who are prescribed the drug have significantly shorter spells. A number of demographic variables have a statistically significant impact on the duration of the work spells. Hence, older workers have shorter spells, irrespective of the destination state. Workers from the northern part of the country have generally shorter work spells, save for transitions into depressions.

The next panel of the table investigates whether past occurrences of migraines and depressions have an impact on the occurrence of future spells. Both variables, \# Past migraines and \# Past depressions, are defined as the total number of completed spells that occurred between January 1996 and the current ongoing spell. ${ }^{18}$ The number of past migraines aggregates both treated and untreated migraine spells into a single index. The parameter estimates show that past migraine occurrences have no impact on the probability that the current migraine lasts less than half a day. On the other hand, it does indicate that the transitions between employment and treated migraine will happen sooner if past migraines are more numerous. This results underscores the chronic nature of the disease. On the other hand, the cumulative number of past depressions has no impact on the duration of the current depression.

The next set of parameter estimates focuses on the days effects. Contrary to earlier findings [Barmby et al. (1991), Card and McCall (1996), Ichino and Moretti (2009)], our estimates show very little "monday" or "friday" effects. If anything, untreated migraines are more likely to last less than

\footnotetext{
${ }^{18}$ Because we do not have any information prior to 1996 , we underestimate the cumulative number of events. The parameter estimate risks being biased unless we assume that only recent events matter in explaining current events.
} 
half a day if they are diagnosed on monday. The parameter estimate is only statistically significant at 6.6\%. As in Barmby et al. (1991), this could reflect a censoring or a "bunching" problem: The migraine spell may have begun over the weekend and care sought only on monday when they are available.

Finally the last section of the table focuses on the impact of subscribing to the BPPO insurance policy and on the impact of medication. Recall that our data does not allow us to distinguish between the insurance policies in terms of cost or coverage. The parameter estimates thus only identifies the effects of this particular policy relative to those of the SelectCare PPO and Blue Standard PPO. Despite the fact that the policies can not be ranked in terms of coverage, the Blue preferred PPO impacts the transitions across the different states in a statistically significant manner. Hence it is found that workers subscribing to the latter are more likely to be away from work for less than half a day than workers subscribing to the other policies. On the other hand, workers subscribing to the BPPO will systematically experiment shorter employment spells, irrespective of the state in which they transit. Thus once we condition for as many covariates as there are available, and once we control for unobserved heterogeneity, we still find that insurance policies may at least partly explain the variation in the duration of absence spells among chronic migraine sufferers. The table also shows that Drug A deceases the probability that a given migraine spell lasts half a day or less. This is consistent with the fact that Drug A may be less efficient in treating severe migraines.

The marginal impact of exogenous variables such as Drug A and BPPO is difficult to ascertain in our model due the complex correlations between the different states. This is better ascertained through numerical simulations to which we now turn.

\subsection{Simulation results}

The unobserved heterogeneity variables capture permanent characteristics that are individual specific and which may impact different outcome variables in a specific manner. Because our regressions include few control variables, it is important to investigate the role played by unobserved heterogeneity in explaining the transitions between spells of work and spells away from work. The best way to achieve this is through stochastic simulations. We first start by drawing 1,000 values of $\xi_{1}$ and $\xi_{2}$ in order to compute each $\nu_{k}$ [see equation (7)]. For each pair of random draws, we next simulate 1,000 three-year work histories for a representative worker in our sample based on the parameter estimates of the model. These are then summarized by com- 
puting the mean duration and frequency of the various states considered in the model.

The algorithm works as follows. We determine the initial state randomly between treated or untreated migraine using a random draw from the normal distribution. Conditional on the initial state, we then compute the duration of the work spell for each possible exit route. The shortest duration then determines the exit route. If depression is the transition state, we compute its duration based on the appropriate parameter estimates. If the exit route is treated or untreated migraine, we compute the probability that the spell lasts less than half a day and compute its duration accordingly. We record the cumulative number of treated and untreated migraines as well as the total number of depressions because the current duration in various states is conditioned upon past occurrences. We repeat the process until the total duration of the sequence reaches 1,095 days. The last spell is censored if it lasts beyond three years. By drawing 1,000 values for both $\xi_{1}$ and $\xi_{2}$ we span their entire distributions.

Table 7 reports the main findings. The simulations are conducted for a male worker who is 40 years of age and reside in a northeastern rural area. When treatment is required, Drug A is prescribed. Likewise, when going through a spell of depression the worker is prescribed an anti-depressant drug. The table is divided in three separate panels. The first focuses on the sensitivity of the duration of work spells and the frequency of migraine spells with respect to the unobserved heterogeneity of the work equation, i.e. $\nu_{k}$, $k=$ Work. The table shows that the outcomes are very sensitive to the value of $\nu_{k}$. The mean duration of an uninterrupted work spell is slightly above a year. ${ }^{19}$ But it varies greatly between the first and the fourth quartiles of the distribution. Not surprisingly, the duration of the work spells and the frequency of the migraine spells are negatively related. ${ }^{20}$

The above relation is not necessarily linear. Figure 3 depicts the (kernel smoothed) relation between $\nu_{k}, k=W$, and the duration and frequency of work and migraine spells. It clearly shows that two identical mean-modal workers may behave entirely differently. One will have very long work spells and rarely miss out on work despite being diagnosed with chronic migraine

\footnotetext{
${ }^{19}$ This is much larger than what is reported in Table 2. Recall that the sample statistics are computed for spells that occur after the first migraine spell. Most workers are thus observed for much less than three years. Furthermore, our simulations are conducted for a representative worker.

${ }^{20}$ The frequencies of migraine spell are higher than those reported in Table 2 for the same reason as mentioned in footnote 19 above.
} 
Figure 3: Work Duration and Migraine Frequencies

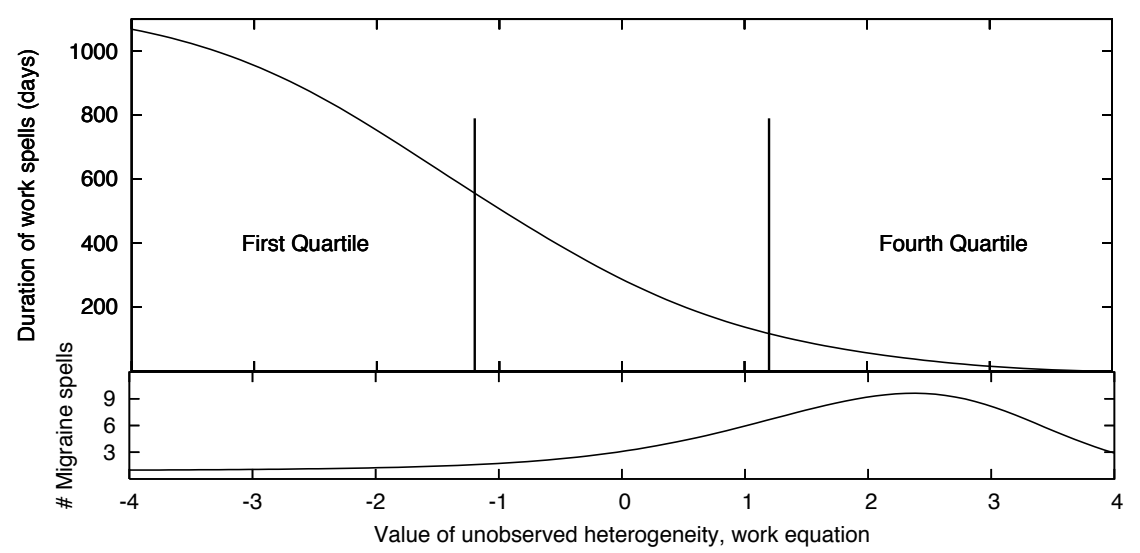

problems. At the other extreme, an observationally identical worker will have very short work spells and be absent from work on a regular basis. The sensitivity of our results to the unobserved heterogeneity components may underscore the fact that our regressions are not controlling for important factors. But it may also be a reflection of the fact that chronic illnesses are intrinsically complex and that such wide variations are to be expected, irrespective of the number of control variables entering the model.

The middle panel of the Table 7 focuses on the relative impact of Drugs A and B. The simulations are conducted by turning the dummy variable Drug A on and off, respectively. It was mentioned earlier that both drugs could be used to treat severe migraines. Drug B was nevertheless usually thought preferable when the migraine was deemed particularly severe. Controlling for drug type may be thus be akin to controlling for severity. The simulations show that there are hardly any differences between the two drugs both in terms of work duration and occurrence of migraine spells. The possibility that work spells and migraine occurrences might have been worse had it not been for Drug B can obviously not be ruled out. Our simulations simply can not account such a counterfactual.

The bottom panel of Table 7 investigates the potential selection bias into the BPPO insurance policy and its consequences on various outcomes. From equations (6) and (7) we can easily establish that

$$
\theta_{k}^{1} \xi_{1}+\theta_{k}^{2} \xi_{2} \geq-X \beta_{I}, k=\mathrm{INS}
$$


is required for BPPO to be selected. The first column of the bottom panel reports the simulation results for draws that satisfy the latter condition while the second column relates to draws that do not. The difference between the two columns is very large. As expecte from Table 6, a worker who subscribes to the BPPO typically has much shorter work spells and more frequent migraine spells than an otherwise comparable fellow worker. The sensitivity of work duration and migraine occurrences relative to $\nu_{k}, k=$ INS, is depicted in Figure 4. The middle vertical line is the threshold value that determines whether BPPO is selected. Workers who subscribe to the $\mathrm{BPPO}$ are to its right and those who subscribe to the BSP/Seclect Care to its left. The differences between the two groups are striking. Despite the small discrete around the threshold, (smoothed) work duration decreases continuously with $\nu_{k}, k=\mathrm{BPPO}$. Likewise, the small discrete decrease in migraine frequency is immediately followed by a continuous increase.

Figure 4: Work Duration and Migraine Frequencies

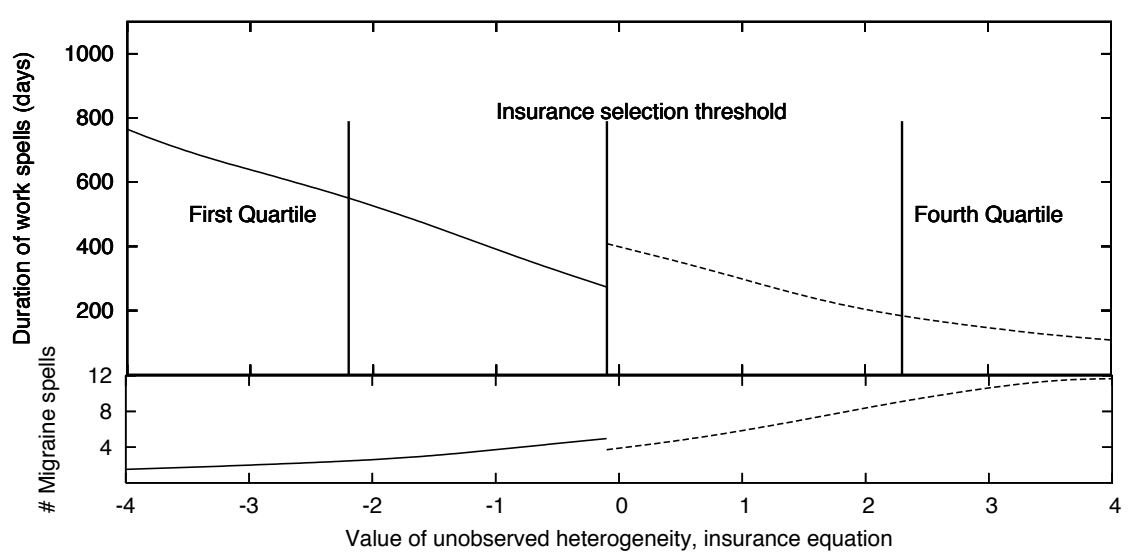

\section{Conclusion}

The research of the past two decades on work absenteeism has focused primarily on moral hazard issues. The empirical literature on health-related work absenteeism has dealt for the most part on acute or temporary illnesses. Surprisingly, the majority of empirical studies do not discriminate between the types of illnesses that prompt workers to stay home or seek care. Yet the incidence and duration of absence spells, and their responsiveness to financial incentives, certainly depend upon the nature of the health shock. 
In this paper we focus on chronic migraine, a common and acute illness that can prove to be relatively debilitating. Our analysis is based upon the absenteeism of workers employed in a large Fortune-100 manufacturing firm in the United States. We model their daily transitions between employment and absenteeism between January 1996 up until December 1998. Only absences due to migraine and depression, its main comorbidity, are taken into account.

Workers in our sample could subscribe to three different insurance packages. Our goal is to determine whether the insurance policies influence the duration of employment and absence spells once we condition on observable and unobservable covariates, on medication and once we take into account potential selectivity into insurance coverage. Our results show that there is very little past occurrence dependence in the data: past migraine and depression spells have little predictive power on the duration of future employment and migraine spells. Perhaps because we focus on a very narrowly defined disease, we do not find any evidence of "monday" or "friday" effects contrary to what is usually found in the literature on absenteeism. As expected, the duration of depression spells, the main comorbidity associated with migraines, varies very little with individual characteristics. Except for the use of antidepressant drugs, not a single covariate depicts any explanatory power on duration. For all intents and purposes, the duration of the depression spells can be considered exogenous from the workers' point of view.

Perhaps more importantly, we do find considerable evidence of correlation between the different states we consider. In particular, workers who are more likely to choose the Blue Preferred Provider Organization (BPPO) insurance policy are also more likely to have shorter employment spells and thus more frequent absence spells. Yet their absence spells are found to be generally shorter than those of workers subscribing to either the SelectCare PPO or the Blue Standard PPO insurance policies. Our results thus provide weak indirect evidence that workers suffering from chronic migraines adapt their work/absence behaviour according to the provisions of the insurance policy they subscribe to. 


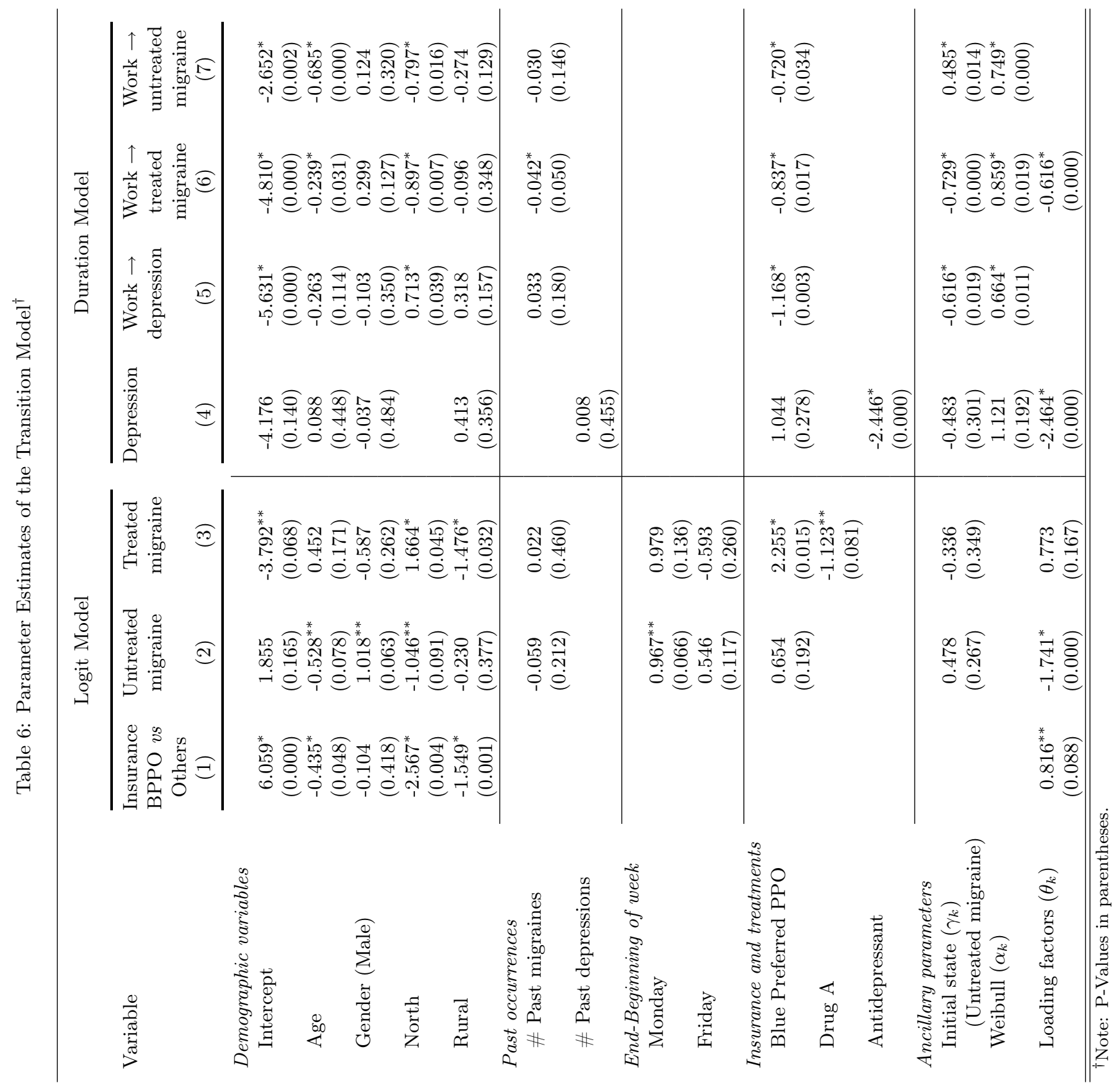


Table 7: Simulation Results

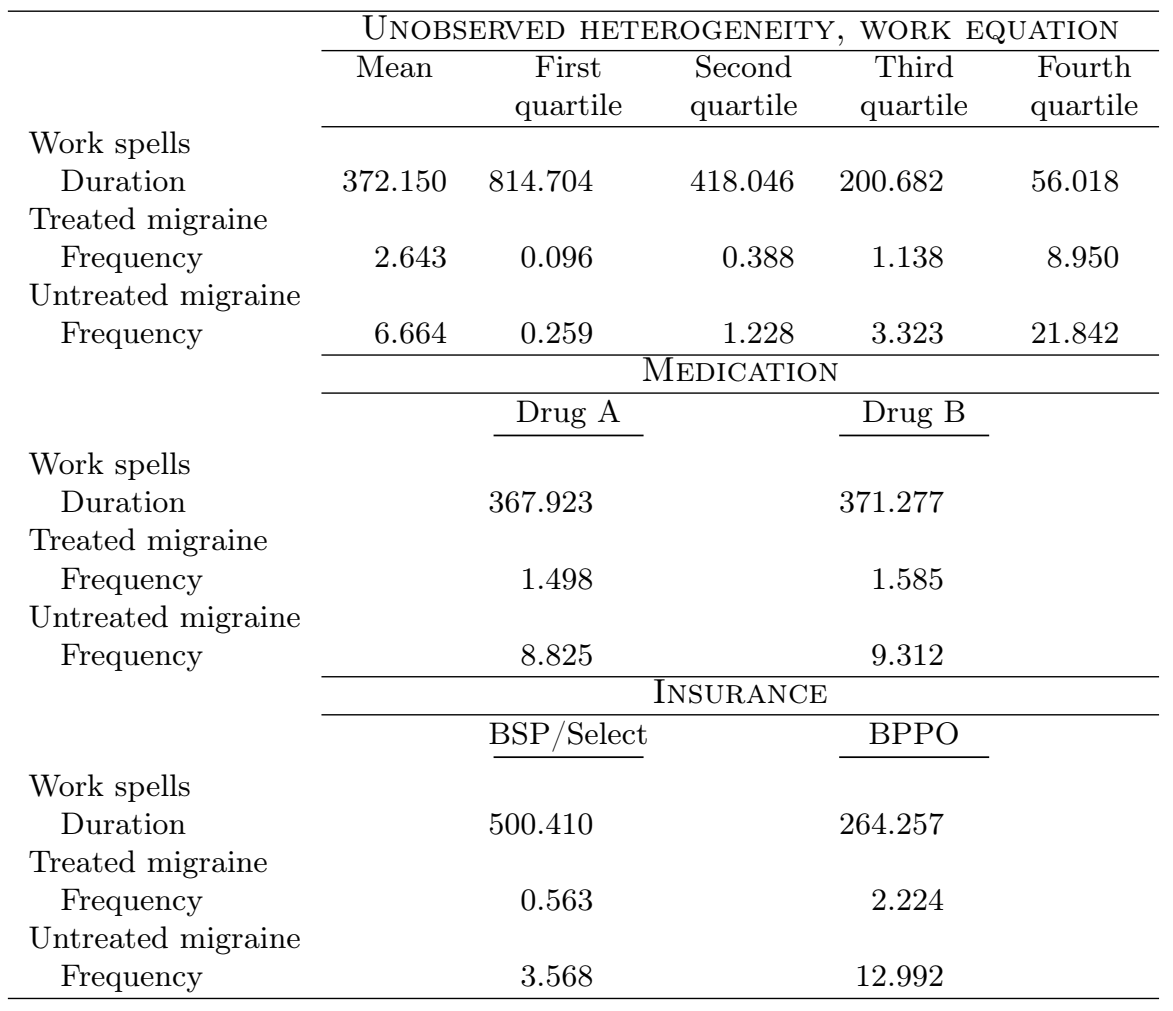




\section{References}

Antonaci, F., Dumitrache, C., De Cillis, I., Allena, M., 2010. A review of current european treatment guidelines for migraine. The Journal of Headache and Pain 11, 13-19. 10.1007/s10194-009-0179-2.

Barmby, T., 2002. Worker absenteeism: a discrete hazard model with bivariate heterogeneity. Labour Economics 9, 469 - 476.

Barmby, T., Ercolani, M., Treble, J., 2004. Sickness absence in the UK 1984-2002. Swedish Economic Policy Review 11, 65-88.

Barmby, T.A., Orme, C.D., Treble, J.G., 1991. Worker absenteeism: An analysis using microdata. The Economic Journal 101, 214-229.

Van den Berg, G., 1997. Association measures for durations in bivariate hazard rate models. Journal of Econometrics 79, 221-245.

Bonnal, L., Fougère, D., Sérandon, A., 1997. Evaluating the impact of French employment policies on individual labour market histories. The Review of Economics Studies 64, 683-718.

Breslau, N., Davis, G., 1993. Migraine, physical health and psychiatric disorder: a prospective epidemiologic study in young adults. Journal of Psychiatric Research 27, 211-221.

Brouillette, D., Lacroix, G., 2010. Heterogeneous treatment and self-selection in a wage subsidy experiment. Journal of Public Economics 94, 479-492.

Brown, S., Fakhfakh, F., Sessions, J.G., 1999. Absenteeism and employee sharing: An empirical analysis based on French panel data, 1981-1991. Industrial and Labor Relations Review 52, 234-251.

Card, D., McCall, B., 1996. Is workers' compensation covering uninsured medical costs? evidence from the monday effect. Industrial and Labor Relations Review 49, 690-706.

Caro, G., Getsios, D., Caro, J., Raggio, G., Burrows, M., Black, L., 2001. Sumatriptan: economic evidence for its use in the treatment of migraine, the canadian comparative economic analysis. Cephalalgia 21, 12-19(8).

Clouse, J.C., Osterhaus, J.T., 1994. Healthcare resource use and costs associated with migraine in a managed healthcare setting. Annals of Pharmacotherapy 28, 659-664. 
Cockburn, I.M., Bailit, H.L., Berndt, E., Finkelstein, S., 1999. Loss of work productivity due to illness and medical treatment. Journal of Occupational and Environmental Medicine 41, 948-953.

Doiron, D., Gorgens, T., 2008. State dependence in youth labor market experiences, and the evaluation of policy interventions. Journal of Econometrics 145, 81-97.

Eberwein, C., Ham, J.C., LaLonde, R.J., 2002. Alternative methods of estimating program effects in event history models. Labour Economics 9, 249-278.

Evans, R., Mathew, N., 2000. Handbook of Headache. Lippincott, William and Wilkins.

Freitag, F.G., Cady, R., DiSerio, F., Elkind, A., Gallagher, R.M., Goldstein, J., Klapper, J.A., Rapoport, A.M., Sadowsky, C., Saper, J.R., Smith, T.R., 2001. Comparative study of a combination of isometheptene mucate, dichloralphenazone with acetaminophen and sumatriptan succinate in the treatment of migraine. Headache: The Journal of Head and Face Pain 41, 391-398.

Gilbert, L., Kamionka, T., Lacroix, G., 2001. Les effets des dispositifs publics de retour à l'emploi destinés aux jeunes hommes défavorisés au Québec. Économie et Statistique 345, 55-94.

Gilleskie, D.B., 1998. A dynamic stochastic model of medical care use and work absence. Econometrica 66, 1-45.

Gilleskie, D.B., 2010. Work absences and doctor visits during an illness episode: The differential role of preferences, production, and policies among men and women. Journal of Econometrics 156, 148 - 163.

Gilleskie, D.B., Lutz, B.F., 2002. The impact of employer-provided health insurance on dynamic employment transitions. The Journal of Human Resources 37, 129-162.

Gouriéroux, C., Monfort, A., 1996. Simulation-Based Econometric Methods. Core Lectures, Oxford University Press.

Gourriéroux, C., Monfort, A., 1991. Simulation based econometrics in models with heterogeneity. Annales d'économie et de statistique 20, 69-107. 
Gritz, R., 1993. The impact of training on the frequency and the duration of employment. Journal of Econometrics 57, 21-51.

Ham, J., LaLonde, R., 1996. The effect of sample selection and intitial conditions in duration models: Evidence from experimental data on training. Econometrica 64, 175-205.

Ham, J., Rea, S., 1987. Unemployment insurance and male unemployment duration in Canada. Journal of Labor Economics , 325-353.

Heckman, J., Singer, B., 1984. A method for minimizing the distributional assumptions in econometric models for duration data. Econometrica, $271-320$.

Henrekson, M., Persson, M., 2004. The effects on sick leave of changes in the sickness insurance system. Journal of Health Economics 22, 87-113.

Ichino, A., Moretti, E., 2009. Biological gender differences, absenteeism, and the earnings gap. American Economic Journal: Applied Economics $1,183-218$.

Johansson, P., Palme, M., 2005. Moral hazard and sickness insurance. Journal of Public Economics 89, 1879 - 1890.

Kamionka, T., 1998. Simulated maximum likelihood estimation in transition models. Econometrics Journal 1, C129-C153.

Kamionka, T., Lacroix, G., 2008. Assessing the External Validity of an Experimental Wage Subsidy. Annales d'Économie et de Statistique 9192.

Laroque, G., Salanié, B., 1993. Simulation-based estimation of models with lagged latent variables. Journal of Applied Econometrics 8, S119-S133.

Lawless, J., 2003. Event history analysis and longitudinal surveys, in: Chambers, R., Skinner, C. (Eds.), Analysis of Survey Data. John Wiley and Sons. chapter 15, pp. 221-243.

Lipton, R., Bigal, M., Diamond, M., Freitag, F., Reed, M., Stewart, W., 2007. Migraine prevalence, disease burden, and the need for preventive therapy. Neurology 68, 343-349. http://www . neurology.org/cgi/reprint/68/5/343.pdf. 
Mealli, F., Pudney, S., 2003. Applying heterogenous transition models in labour economics: The role of youth training in labour market transitions, in: Chambers, R., Skinner, C. (Eds.), Analysis of Survey Data. John Wiley and Sons. chapter 16, pp. 245-274.

National Headache Foundation, $2010 . \quad$ Migraine facts. http://www.headaches.org/press/NHF_Press_Kits/Press_Kits__Migraine_Facts.

Nguyen, S.V., Zawacki, A.M., 2009. Health insurance and productivity: Evidence from the manufacturing sector. CES 09-27 Working Paper.

Pryse-Phillips, W., Findlay, H., Tugwell, P., Edmeads, J., Murray, T., Nelson, R., 1992. A canadian population survey on the clinical, epidemiologic and societal impact of migraine and tension-type headache. The Canadian journal of neurological sciences 19, 333-339.

Puhani, P.A., Sonderhof, K., 2010. The effects of a sick pay reform on absence and on health-related outcomes. Journal of Health Economics 29, $285-302$.

Schulman, K.A., Yabroff, K.R., Kong, J., Gold, K.F., Rubenstein, L.E., Epstein, A.J., Glick, H., 2001. A claims data approach to defining an episode of care. Pharmacoepidemiology and Drug Safety 10, 417-427.

Schwartz, B.S., Stewart, W.F., Lipton, R.B., 1997. Lost workdays and decreased work effectiveness associated with headache in the workplace. Journal of Occupational and Environmental Medicine 39, 320-327.

Senaratne, R., Van Ameringen, M., Mancini, C., Patterson, B., Bennett, M., 2010. The prevalence of migraine headaches in an anxiety disorders clinic sample. CNS Neuroscience and Therapeutics 16, 76-82.

US Headache Consortium, 2000. Evidence-Based Guidelines for Migraine Headache in the Primary Care Setting: Pharmacological Management of Acute Attacks. Technical Report. American Academy of Neurology.

Vistnes, J.P., 1997. Gender differences in days lost from work due to illness. Industrial and Labor Relations Review 50, 304-323.

Wilper, A., Woolhandler, S., Himmelstein, D., Nardin, R., 2010. Impact of insurance status on migraine care in the United States: a population-based study. Neurology 74, 1178-1183. 
Wooldridge, J.M., 2005. Simple solutions to the initial conditions problem in dynamic, nonlinear panel data models with unobserved heterogeneity. Journal of applied econometrics 20, 39-54.

Ziebarth, N.R., Karlsson, M., 2010. A natural experiment on sick pay cuts, sickness absence, and labor cost. Journal of Public Economics 94. 